\title{
Information on nutritional supplement labels: time for legislation?
}

\author{
Gabriels G, MSc, Division of Clinical Pharmacology, Department of Medicine, University of Cape Town \\ Lambert M, PhD, MRC/UCT Research Unit for Exercise Science and Sports Medicine, Department of Human Biology, University of Cape Town \\ Smith P, PhD, Division of Clinical Pharmacology, Department of Medicine, University of Cape Town \\ Correspondence to: Gary Gabriels, e-mail: gary.gabriels@uct.ac.za \\ Keywords: nutritional, supplements, contaminants, claims, legislation, labelling
}

\section{Abstract}

Background: Nutritional supplements have received attention both from food manufacturers, as a means of marketing the added value to health; and from consumers, in terms of awareness, education, and improved health. To assist this process, it is important to have specific knowledge and understanding of the claims made on labels of nutritional supplement products used for general, and more specifically, for sports consumers. The industry is not regulated, and therefore the claims that are made may not always be accurate.

Method: The aim was to describe the labelling and claims information on the labels of a select group of nutritional supplements, either manufactured in, or imported into South Africa. Specific predetermined categories of labelling and claims made on the containers were assessed and summarised.

Results: Forty products were selected for analysis, of which 21 (53\%) were locally assembled or manufactured products, and 19 (48\%), international imported products. Ninety-five per cent of products contained a warning statement on the label. Eighty-five per cent of the nutritional supplement products had a disclaimer on the label. Ninety-eight per cent of the nutritional supplement product labels included some claim on the label.

Conclusion: The following information, in particular, needs to be regulated and enforced as part of the labelling process, to ensure that the consumer can make an informed choice. This includes highlighting the potential for adverse events, encouraging warning statements pertaining to "exclusion of use, and "not a cure for disease states", and alerting consumers of the potential for the presence of banned substances, based on laboratory screen methods.

\section{Introduction}

Nutritional supplements have received attention, both from manufacturers as a means of marketing the added value to health; and from consumers, in terms of awareness, education, and improved health. A supplement is a product taken orally that contains a "dietary ingredient" intended to supplement the diet. The "dietary ingredients" in these products may include vitamins, minerals, herbs, or other botanicals, amino acids, and substances, such as enzymes, organ tissues, glandulars, and metabolites. ${ }^{1}$

The regulatory framework of nutritional supplements should be compatible with public health and safety, protect the consumer, promote fair trade, and encourage innovation. ${ }^{2-4}$ Consumer structures need to play a greater role in the development of a sound nutritional supplement management system, to ensure that appropriate legislation and regulation are developed and enforced on a sustainable basis, in line with the Consumer Protection Act (CPA) 68 of $2008 .^{5}$
Section 29 of the CPA specifically states that a producer, importer, distributor, retailer or service provider, must not market any goods or services in a manner that is reasonably likely to imply a false or misleading representation, and that is misleading, fraudulent or deceptive in any way. Section 41 of the CPA specifically provides, and outlines, how claims that have been made could be affected. ${ }^{5}$

The South African Medical Control Council published a August 2011 guideline for comment, with regard to the quality, safety, and efficacy of complementary medicine. This guideline and its implementation could have relevance, and apply to nutritional supplements when it becomes law. If the specific scheduled complementary medicine or active ingredients that have an established identity and tradition of use, determined or known, are not declared on the label, or when claims are made, and are not clearly substantiated by peer-review scientific processes, a legal challenge could result. ${ }^{6}$

The concern among health professionals is that the supplement industry in South Africa is currently not regulated sufficiently. These 
products are categorised as nutritional supplements, and as such, do not need to undergo rigorous testing to confirm safety and efficacy. In South Africa, a 2004 survey detected that 12 (40\%) out of 30 overthe-counter nutritional supplements contained banned substances, such as ephedrine. ${ }^{7,8}$

To assist this process, it is important to have specific knowledge and understanding of the claims made on the labels of nutritional supplements products used for general, and more specifically, sports consumers. In particular, labelling information, including warnings, claims, disclaimers, as well as proposed mechanisms of action, needs to be documented.

All this information is needed for practical intervention, policy development, and possible appropriate legislation and regulation. Such information may also further provide and facilitate the design of guidelines on how nutritional supplement products may be marketed in future, and ensure that the consumer makes informed choices. In accordance with these points, the aim of this study was to select a group of nutritional products, either imported, or manufactured in South Africa, and quantify the labelling and claims information on the labels.

\section{Method}

Nutritional supplement products were purchased at Century City Dischem Pharmacy in Canal Walk, Cape Town, Western Cape, South Africa. They consisted of internationally imported, and locally manufactured or assembled products, based on the list of top sellers as determined by sales at the Dischem store purchased, and within the available budget for the project. Labelling information and claims that appeared on the containers were assessed according to specific predetermined categories. ${ }^{9-18}$

The categories included claims made on containers, general information, disclaimers, warnings, quality assurance, scientific pledge, and consumer or public relations categories.

The supplements were assessed for each category, and the information transcribed into a Widows-based Microsoft ${ }^{\circledR}$ Office Excel 2003 SP 1 (Exce $^{\odot}, 1985-2003$ Microsoft Corporation) spreadsheet, for each of the nutritional supplement product labels. The statements were then captured as "yes" or "no" statements. The Excel file was imported to Statistica Version 10 (Stat Soft Inc ${ }^{\circledR} 1984-2011$ Stat Soft Inc) for statistical analysis.

\section{Results}

Forty products were selected for analysis, of which $21(53 \%)$ were locally assembled or manufactured products, and 19 (48\%), international imported products. The formulations consisted of powders $(40 \%)$, capsules (33\%), tablets (20\%), and liquid in capsules (8\%). Only $10 \%$ of the product labels cited a literature reference, and of these, $75 \%$ cited studies carried out in humans. Thirty per cent of the products contained a statement on the labels indicating that the product was "contaminant -free".

Ninety-five per cent of the nutritional supplements referred to a website on their labels. All the products provided information with the directions for use. Ninety-five per cent had a "best before" date and expiry date for the consumption of the specific product and 95\% had batch numbers on the nutritional supplement labels. The mean number of ingredients/compounds described on each label was 28 , with a range of 1 to 88 . There was an average of five colours (ranging from three to nine) on each label.

Ninety-five per cent of products carried a warning statement on the label. Often, these statements were printed in a small font size, and were not immediately noticeable. The number of warnings ranged from none to 14 per product, with a mean of five. The warning categories on nutritional supplement labels assessed in this study are shown in Table I.

Table I: The 17 warning categories assessed on the product labels $(n=40)$

\begin{tabular}{|l|c|c|}
\hline Warning descriptions & Total & $\%$ \\
\hline Keep product out of reach of children & 27 & 68 \\
\hline Importance of adherence to storage details & 23 & 57 \\
\hline Use during pregnancy and lactation & 17 & 43 \\
\hline Exceeding recommended dose & 17 & 43 \\
\hline Importance of consultation with healthcare professionals & 17 & 43 \\
\hline Age categories for consumption & 12 & 30 \\
\hline Lower dose when experiencing adverse events & 10 & 25 \\
\hline Nutritional supplements should not replace dietary & 10 & 25 \\
\hline requirements & & 10 \\
\hline Potentiate and suppress the effect of drugs & 25 \\
\hline Certain medical conditions and the use of supplements & 10 & 25 \\
\hline Importance of staying hydrated & 8 & 20 \\
\hline Time restriction consideration when consuming product & 4 & 10 \\
\hline Maximum dose "dangers" & 4 & 10 \\
\hline Presence of banned substances in the supplements & 2 & 5 \\
\hline Presence of food items associated with allergies or & 2 & 5 \\
\hline Product is gender specific & & 2 \\
\hline Exclusion of use, and not a cure for disease & 1 & 2 \\
\hline
\end{tabular}

Eighty-five per cent of the nutritional supplement products contained a disclaimer on the label. A disclaimer was defined as any statement intended to specify or delimit the scope of rights and obligations that may be exercised and enforced by parties in a legally recognised relationship. Table II represents the disclaimers that were observed on the product labels in this study.

Table II: Disclaimers on product labels $(n=40)$

\begin{tabular}{|l|c|c|}
\hline Disclaimer descriptions & Total & $\%$ \\
\hline The product does not cure illness & 21 & 52 \\
\hline $\begin{array}{l}\text { The product is free of stimulants, colourants, flavourants } \\
\text { or preservatives }\end{array}$ & 16 & 40 \\
\hline $\begin{array}{l}\text { The product, or claim made by the product, has not been } \\
\text { evaluated by the US Food and Drug Administration }\end{array}$ & 12 & 30 \\
\hline \begin{tabular}{l} 
The product should not replace medication \\
\hline
\end{tabular} & 7 & 18 \\
\hline
\end{tabular}


Ninety-eight per cent of the nutritional supplement products labels included a claim on the label. The different categories and numbers of supplements within each category are shown in Table III.

Table III: Description of the specific claims on the product labels $(n=40)$

\begin{tabular}{|c|c|c|}
\hline Claim descriptions & Total & $\%$ \\
\hline Quality of the product emphasis & 22 & 45 \\
\hline Muscle mass changes & 19 & 47 \\
\hline Provides increased energy & 17 & 43 \\
\hline Use of pseudo-scientific terms (Table IV) & 15 & 38 \\
\hline Will increase physical performance & 15 & 37 \\
\hline Provides increased strength & 13 & 33 \\
\hline Improves recovery & 13 & 32 \\
\hline Supports general metabolism & 12 & 30 \\
\hline Supports fat metabolism & 7 & 18 \\
\hline Can have an effect on mood changes & 7 & 18 \\
\hline Outrageous claims (Table IV) & 7 & 17 \\
\hline Supports cognitive function & 6 & 15 \\
\hline Serves as a weight loss or management product & 5 & 12 \\
\hline Removal of metabolic by-products & 5 & 12 \\
\hline Serves as an appetite suppressant & 4 & 10 \\
\hline Supports glucose metabolism & 4 & 10 \\
\hline Supports testosterone metabolism & 4 & 10 \\
\hline Gives support to the immune system & 4 & 10 \\
\hline Provides antioxidant properties & 4 & 10 \\
\hline Research supports evidence & 4 & 10 \\
\hline Serves as a meal replacement & 2 & 5 \\
\hline Relieves stress & 2 & 5 \\
\hline Could alter libido & 2 & 5 \\
\hline
\end{tabular}

All the nutritional supplement products labels (100\%) contained some scientific indication or pledge, and $60 \%$ of the nutritional supplements included scientific or research claims on the labels. These claims were not necessarily peer-reviewed.

Forty per cent of the supplements had pledges or an indication of commitment to the nutritional supplements assessed, and $35 \%$ made a pronouncement on a specific technology or specific patent used in the manufacture of the nutritional supplement. Thirty-three per cent of the nutritional supplement products contained advertising on the label, and eight per cent of the nutritional supplement products provided a link to social networks, e.g. facebook, twitter.

Table IV provides examples of assessed selected categories.
Table IV: Examples of selected categories

\begin{tabular}{|c|c|}
\hline Category & Examples \\
\hline Outrageous claims & $\begin{array}{l}\text { Instant muscle gratification } \\
\text { No loading, no cycling, no side-effects } \\
\text { The "last word" in ultra-enhancing sports supplements }\end{array}$ \\
\hline Pseudo-science & $\begin{array}{l}\text { Activates metabolism and shreds fat } \\
\text { Ignites intense workouts } \\
\text { Triggers anabolism and builds muscle } \\
\text { Natural thyroid support complex supports and enhances } \\
\text { metabolism }\end{array}$ \\
\hline $\begin{array}{l}\text { Scientific, research } \\
\text { and pledge } \\
\text { terminology }\end{array}$ & $\begin{array}{l}\text { Scientifically formulated } \\
\text { Scientifically formulated for professional athletes } \\
\text { National Academy of Sciences } \\
\text { New formula, with the latest clinically researched } \\
\text { ingredients }\end{array}$ \\
\hline $\begin{array}{l}\text { Strongly worded } \\
\text { terminology }\end{array}$ & $\begin{array}{l}\text { Anabolic hormone enhancer } \\
\text { High potency } \\
\text { The power of science }\end{array}$ \\
\hline $\begin{array}{l}\text { Specific } \\
\text { technology or } \\
\text { specific patent }\end{array}$ & $\begin{array}{l}\text { Advanced liquid delivery technology maximises } \\
\text { bioavailability } \\
\text { Patent-pending nano-diffuse technology } \\
\text { Patent creatine stabilisation technology }\end{array}$ \\
\hline Claims & $\begin{array}{l}\text { Improves glucose metabolism, lipotropic agent, red blood } \\
\text { cell and oxygen booster } \\
\text { We only use superior ingredients, sourced from } \\
\text { international raw material suppliers } \\
\text { We take your physical performance to the next level }\end{array}$ \\
\hline Disclaimers & $\begin{array}{l}\text { This product does not intend to prevent, or cure, any } \\
\text { form of illness or disease, and should not replace any } \\
\text { medication } \\
\text { These statements have not been evaluated by the US } \\
\text { Food and Drug Administration } \\
\text { The capsules contain no banned substances, illegal } \\
\text { stimulants, caffeine, gluten, preservatives, colouring } \\
\text { agents, yeast or lactose }\end{array}$ \\
\hline $\begin{array}{l}\text { Indication of } \\
\text { commitment }\end{array}$ & $\begin{array}{l}\text { With formulation based on the latest scientific research } \\
\text { available, our aim is to ensure that our products are } \\
\text { unsurpassed in quality, potency and efficacy } \\
\text { A copy of the laboratories' certificate of analysis for each } \\
\text { lot can be supplied } \\
\text { We make an unconditional pledge to you, our valued } \\
\text { customer, to continually supply you with products of the } \\
\text { highest quality and purity }\end{array}$ \\
\hline Advertising & $\begin{array}{l}\text { Learn about our products, obtain diet information, and } \\
\text { chat with members. You can also win great prizes } \\
\text { Foundational, "core" nutrition provides the basic } \\
\text { nutritional framework for any lifter who is serious about } \\
\text { iron warfare } \\
\text { If this product doesn't meet with your standards for any } \\
\text { reason, take the remainder back, with your receipt, to } \\
\text { where you bought it from, for a full refund or exchange } \\
\text { No questions asked }\end{array}$ \\
\hline Warnings & $\begin{array}{l}\text { Maximum dose "dangers" } \\
\text { Keep product out of reach of children } \\
\text { The importance of adherence to storage details }\end{array}$ \\
\hline Contaminant-free & $\begin{array}{l}\text { Stimulant-free } \\
\text { Ephedrine-free } \\
\text { No artificial flavours } \\
\text { No artificial colourants } \\
\text { No preservatives } \\
\text { Ingredients free of all impurities and by-products }\end{array}$ \\
\hline
\end{tabular}




\section{Discussion}

This study has provided diverse examples of the labelling of nutritional supplements. The 40 nutritional supplement products that were assessed as part of this study yielded the following information.

Seventy per cent of the nutritional supplement product labels provided no indication or evidence that the product was "contaminant-free". This can be interpreted as either an expression of confidence that the quality of the products are good, and therefore there is no concern about possible contamination, or that the manufacturer is unaware of possible contaminants in the products. This suggests that it is important to carry out screen testing of products to verify whether or not nutritional supplements contain contaminants, with specific regard to steroids and stimulants. Even if "contaminant-free" information is included on labels, this does not guarantee that the products are free of contaminants, especially as these products are produced in an environment that is not governed by manufacturing regulations. Although the label may state that the product is stimulant-free, no legislation exists to monitor the accuracy of this statement. Furthermore, the word "stimulant" may also be used in a generic way. Therefore, certain stimulants may be absent, while others may be present, either unintentionally, or deliberately, due to the manufacturing process. ${ }^{19,20}$

Of the nutritional supplements assessed, 95\% carried warning statements. On average, there were five warnings per supplement. One supplement contained 14 warnings. The two most frequently used warning statements on the assessed product labels were: "Keep this product out of the reach of children" $(68 \%)$, and "It is important to adhere to the storage details" $(57 \%)$. Both these warnings alert the consumer to potential harm. However, often the children alert did not give a specific age. Less common warning statements, but possibly of greater significance were: "Exclusion of use, and not a cure for disease states" (2\%), and the "Presence of banned substances in the supplements $(5 \%)$ ". With regard to the former, products may contain contaminants that could directly, or indirectly, contribute to, or exacerbate, specific disease states. The latter might affect professional athletes, who could test positive for a banned substance after ingesting a supplement. The potential implication for the general consumer is the impact on long-term health consequences, due to harmful, continuous, intermittent-use effects, or the accumulative effects over time.

In Australia and New Zealand, new labelling initiatives pertaining to food standards require mandatory nutrition information panels. Substances that may cause adverse reactions have to be highlighted on the label. In context, this approach to labelling could also have similar application to nutritional supplement products. ${ }^{21}$

Incorrect storage of the nutritional supplement product, e.g. the wrong temperature, has the potential to convert "active" chemical compounds to other active or inactive chemical moieties, or completely harmful unknown compounds. ${ }^{19}$ The consequence of consumption of such nutritional supplement products could be adverse events. The same logic applies to the consumption of gender-specific products, if not labelled adequately for a specific sex. Unintended consequences that impact on the physiological hormonal balance of a specific sex may occur if compounds that are present in the supplements are not declared on the label. ${ }^{22-24}$

Consumers who fail to comply with the directions for use, could also predispose themselves to the long-term effects of elevated accumulative doses. This could cause adverse effects due to abnormal physiological or normal cell disruptive activity.

Industry-sector, standardised batch number coding on nutritional supplement products, with a data trail from the manufacturing process to the consumer environment, would be useful. Such an approach would facilitate good manufacturing practice (GMP) processes, and should also identify potential contaminant entry points.

Although best-before and expiry date information is valuable, in many cases, it was not clearly visible on the label. In the context of warning statements, a recent study designed to determine nutrition knowledge, and understanding of nutritional information, concluded that only $27 \%$ of respondents looked at package information before making a decision. ${ }^{25}$ Another study suggested that older, as opposed to younger consumers, detect information changes less readily. ${ }^{22}$ Thus, newly-added information does not necessary reach all consumers, and this poses a potential problem for policy makers and scientists. ${ }^{26}$

A study designed to determine the factors that draw consumers' attention to nutritional labels showed that the display size, colour scheme, and familiarity with the label, the logo and its location on the front of the pack, are key determinants. ${ }^{27}$ The study revealed that when consumers have a sound understanding of nutrition information, and gave their attention to the label content, this impacted on nutritional supplement choice. ${ }^{27}$

An off-label promotion study concluded that the media helps shape public perceptions, and increases support for regulatory actions. ${ }^{28}$ "Off-label" is defined as a drug or product used for indications that are not approved by the US Food and Drug administration (FDA). This study concluded that primary concerns about label content include legal concerns, lack of safety or efficacy data, and having no ethical, or clinical content. Having this type of information on the label would ensure that policy and decision makers, healthcare professionals, patients, and the general public, are able to gather sufficient knowledge to make informed choices. ${ }^{28}$ The findings in this study are supported by a study that suggests that nutrition education can be instrumental in encouraging, stimulating, motivating, and providing technical help for consumers. ${ }^{29}$ Technical messages should include teaching consumers simple rules to interpret label information, and to incorporate the information into planning. ${ }^{29}$ Other alternative preventative approaches, as well as improved label design for the purposes of providing nutritional information, should be researched and implemented, if results show these to be more effective. ${ }^{30}$

From this study, it may be concluded that ongoing screen testing of nutritional supplement products is important. In particular, the products would need to be tested batch to batch for contaminants, including steroids and stimulants. The presence and quantity of the ingredients on the label would also need to be verified. Peerreview scientific evidence would ensure relevant engagement with 
social media networks, and provide education and awareness to the consumer in an informed way. This would also emphasise the importance of relevant screening of the "knowns" with regard to number of ingredients on the label information (both qualitatively and quantitatively), and "unknowns", to be determined or discovered, but not reflected on the label information.

This study highlighted concerns about claims and labelling, but the apprehension is compounded by the lack of structures of governance and policy development, that need to ensure the transition from selfregulation to enhanced regulation of the nutritional supplement sector. The importance of screen testing for contaminants and adulterants, and in particular, steroids and stimulants, is apparent.

\section{Conclusion}

The following information needs to be regulated, and enforced with regard to the labelling process to ensure that consumers can make informed choices:

- Highlighting the potential for adverse events, by providing this information on the label

- Warning statements such as: "Keep this product out of reach of children", and "It is important to adhere to storage details" should be included on all labels in an appropriate way, using an acceptable font and visibility.

- Warning statements, such as: "Exclusion of use, and not a cure for disease states", and "Sportsmen should note that there are banned substances in the supplements", should be encouraged. These statements should be based on standardised laboratory screen methods.

- A nutritional supplement sector-specific system and guideline with regards to the best-before and expiry-date information, batch numbers, and GMP, that will also facilitate batch-to-batch laboratory screen testing, should be determined and established.

- An alternative label design, that would be beneficial with regard to providing relevant information to the consumer, needs to be scientifically explored and researched.

\section{Acknowledgements}

The Medical Research Council and the University of Cape Town research committee are hereby acknowledged.

\section{Declaration}

No conflict of interest exists.

\section{References}

1. Plenary presentation. Rationale and scientific support for health claims on foods. S Afr J Clin Nutr. 2005;18(2): 98-101.

2. Gruber J, Brooke-Taylor S, Goodchap J, McCullum D. Regulation of food commodities in Australia and New Zealand. Food Control. 2003;14:367-373.
3. Yee SK, Chu SS, Xu Y, Choo P. Regulatory control of Chinese proprietary medicines in Singapore. Health Policy. 2005;71(2):133-149.

4. Gabriels G, Lambert M, Smith P, Hiss D. Will the new Consumer Protection Act prevent nutritional supplement users from harm? S Afr Med J. 2011;101(8):543-545.

5. Le Maitre D, Gelderblom C, Maphasa L, et al. Communicating the value of fynbos: results of a survey of stakeholders. Ecological Economics. 1997;22:105-121.

6. Sobal J, Marquart L.Vitamin/mineral supplement use among athletes: a review of the literature. Int J Sport Nutr. 1994:4(4):320-334.

7. Philen R, Ortiz D, Auerbach S, Falk H. Survey of advertising for nutritional supplements in health and bodybuilding magazines. JAMA. 1992;268(8):1008-1011.

8. Nieper A. Nutritional supplement practices in the UK junior track and field athletes. Br J Sports Med. 2005;39(9):645-649.

9 Nieman D, Gates J, Butler J, et al. Supplementation patterns in marathon runners. J Am Diet Assoc. 1989:89(11):1615-1619

10. Sobal J, Marquart L.Vitamin/mineral supplement use among high school athletes. Adolescence. 1994;29(116):835-843

11. Slater G, Tan B, Teh K. Dietary supplementation practice of Sigaporean athletes. Int J Sport Nutr Exerc Metab. 2003;13(3):320-332

12. Morrison $L$, Gizis $F$, Shorter B. Prevalent use of dietary supplements among people who exercise at a commercial gym. Int J Sport Nutr Exerc Metab. 2004;14(4):481-492.

13. Eldrige AL, Sheehan ET. Food supplement use and related beliefs: survey of community college students. J Nutr Educ. 1994:26:259-265.

14. Krumbach CJ, Ellis DR, Driskel JA. A report of vitamin and mineral supplement use among university athletes in a Division I institution. Int J Sports Nutr. 1999;9(4):416-425

15 Van der Merwe PJ, Grobbelaar E. Unintentional doping through the use of contaminated nutritional supplements. S Afr J Med. 2005;95(7):510-511.

16. Van der Merwe PJ, Kruger HS. Drugs in sport: results of the past 6 years of dope testing in South Africa. S Afr J Med. 1992;82(3):151-153

17. Rumble T, Wallace A, Deeps C, et al. New food labeling initiatives in Australia and New Zealand. Food Control. 2003;14:417-427.

18. Martin WR, Sloan JW, Sapira JD, Jasinski DR. Physiologic, subjective, and behavioural effects of amphetamine, methamphetamine, ephedrine, phenmetrazine, and methylyphenidate in man Clin Pharmacol Ther 1971:12(2):245-258.

19. Sidney KH, Lefcoe NM. The effects of ephedrine on the physiological and psychologica responses to submaximal and maximal exercise in man. Med Sci Sports. 1977;9(2):95-99.

20. Mclean C, Graham TE. Effects of exercise and thermal stress on caffeine pharmacokinetics in men and eumenorrheic women. J Appl Physiol. 2002;93(4):1471-1478.

21. Grunert K, Wills J, Fernandez-Celemin L. Nutrition knowledge, and use and understanding of nutrition information on food labels among consumers in the UK. Appetite. 2010;55(2):177-189.

22. Gaschler R, Mata J, Stormer V, et al. Change detection for new food labels. Food Quality and Preference. 2010;21:140-147.

23. Bialkova S, van Trijp H. What determines consumer attention to nutritional labels? Food Quality and Preference. 2010;21:1042-1051.

24. Joshi A, Patel A, Holford D. Media coverage of off-label promotion: a content analysis of US newspapers. Res Social Adm Pharm. 2011;7(3):257-271.

25. Lin C, Lee J, Yen S. Do dietary intakes affect search for nutrient information on food labels? Social Science and Medicine. 2004;59(9):1955-1967.

26. Berning J, Chouinard $\mathrm{H}$, Manning $\mathrm{K}$, et al. Identifying consumer preferences for nutrition information on grocery store shelf labels. Food Policy. 2010;35:429-436.

27. The Dietary Supplement Health and Education Act of 1994 [homepage on the Internet]. c2011. Available from: ww.fda.gov/opacom/laws/dshea.html

28. South African Medicines Control Counci. Complimentary medicines: quality, safety, and efficacy guideline [homepage on the Internet]. c2011. Available from: http://www.mccza.com/ dynamism

29. Ahrendt DM. Ergogenic aids: counseling the athlete. Am Fam Physician. 2001;63(5):913-922.

30. Meltzer S, Kohler R, Jakoet I, Noakes T. A practical guide to the use of nutritional supplements in South Africa. Cont Med Educ. 2004:22(3):142-144. 